\title{
A Study on Microhardness, Microstructure and Wear Properties of Plasma Transferred Arc Hardfaced Structural Steel with Titanium Carbide
}

\author{
Balamurugan Sivaramakrishnan, Murugan Nadarajan \\ Department of Mechanical Engineering, Coimbatore Institute of Technology, Coimbatore, India \\ Email: balu74_cit@yahoo.co.in, murugan@cit.edu.in
}

Received 20 January 2014; revised 24 February 2014; accepted 6 March 2014

Copyright (C) 2014 by authors and Scientific Research Publishing Inc.

This work is licensed under the Creative Commons Attribution International License (CC BY). http://creativecommons.org/licenses/by/4.0/

(c) (i) Open Access

\begin{abstract}
The Plasma Transferred Arc (PTA) hardfacing allows for homogeneous refined microstructure, low distortion and dilution resulting on enhanced surface properties when compared to hardfacing by conventional welding processes. This paper deals with PTA surfacing of a structural steel with a consumable containing $\mathrm{TiC}$. $\mathrm{TiC}$ is a very hard refractory material finding increasing usage for wear resistance application. The composition and amount of heat input evidently affect the microstructure and properties of the hardfacing. The microstructure and microhardness of PTA hardfaced structural steel with $\mathrm{TiC}$ were investigated at different heat input conditions across the various zones. The influence of hardfacing parameters on the resulting microstructure, microhardness and wear resistance performance was evaluated. Wear resistance of the hardfaced surface was increased significantly.
\end{abstract}

\section{Keywords}

PTA Hardfacing, Microhardness, Microstructure, Wear Resistance

\section{Introduction}

Hardfacing is a technique used to enhance surface properties of a metallic component as a specially designed alloy is surface welded in order to achieve specific wear properties [1]-[4]. Surface properties and quality of hardfacing depend upon the selected alloy and deposition process. Among the process employed for hardfacing, 
Plasma Transferred Arc (PTA) allows for homogeneous mixture and refined microstructure, low distortion and dilution, resulting on enhanced surface properties [5]-[7]. A significant advantage of PTA hardfacing over traditional hardfacing welding processes is that the consumable material used in powder form [8].

The quality of the hardfacing primarily depends upon the hardness of the interface which is primarily governed by the heat input. It is known that one of the most important parameters controlling the wear behavior of the material is hardness [9]. Greater the hardness, greater will be the abrasion resistant of the materials. The strong interaction with the substrate during hardfacing requires analysis of each alloy system to optimize its properties and weldability. These hardfacings are used for several applications such as high temperature turbine for aerospace application, cutting tools, wear resistance surfaces on large agricultural, textile equipment petrochemical and pharmaceutical industries [10]-[13]. As TiC particles are useful for enhancing wear resistance, they have been widely used to improve surface characteristics.

TiC can be deposited by plasma transferred arc welding process and it has a strong interaction with the substrate, which determines the final microstructure and properties of hardfacing [14] [15]. The mechanical properties of hardfacing are directly related to its microstructure. Due to the difference in range of melting temperature between the substrate and hardfacing metal the dilution of the hardfaced layer could be significantly affected. When dilution is altered, it will influence the resulting microhardness and microstructure of the hardfacing.

The heat-affected zone (HAZ) is the area of base material, which has had its microstructure and properties altered by hardfacing operations. The heat from the hardfacing process and subsequent re-cooling causes this change from the weld interface to the termination of the sensitizing temperature in the base metal. The extent and magnitude of property change of base material depend primarily on the base material and the amount and concentration of heat input by the hardfacing process [16].

The thermal diffusivity of the base material plays a large role-if the diffusivity is high, the material cooling rate is high and the HAZ is relatively small. Alternatively, a low diffusivity leads to slower cooling and a larger HAZ. The amount of heat inputted by the hardfacing process plays an important role. To calculate the heat input for arc welding procedures, the following formula is used:

$$
Q=\left(\frac{V * I * 60}{S * 1000}\right) * \text { effciency }
$$

where $Q=$ heat input $(\mathrm{kJ} / \mathrm{mm}), V=$ voltage $(\mathrm{V}), I=$ current $(\mathrm{A})$, and $S=$ welding speed $(\mathrm{mm} / \mathrm{min})$. The efficiency depends on the welding process used. For PTA hardfacing efficiency is taken as 0.6 [17].

In this investigation, TiC was deposited on structural steel plates at low, medium and high heat input conditions by the PTA process and the hardfacings were characterized with the help of microhardness, microstructural and wears resistance analysis.

\section{Experimental Procedure}

The substrate material selected for the PTA hardfacing was IS: 2062 structural steel. The chemical composition of IS: 2062 structural steel and hardfacing alloy is presented in Table 1.

Using PTA hardfacing system, Titanium Carbide (TiC) was deposited onto the structural steel plate of size $150 \mathrm{~mm} \times 100 \mathrm{~mm} \times 25 \mathrm{~mm}$. This was done by changing the welding parameters to achieve different heat input conditions: low, medium and high. Single hardfacing bead was laid on each plate. Samples were prepared from each hardfaced plate by cutting them at their centre perpendicular to hardfacing direction. Standard metallurgical procedures were employed to prepare the samples from PTA hardfacing deposited at different heat input condi-

Table 1. Chemical composition of base metal and hardfacing alloy.

\begin{tabular}{ccccccccccc}
\hline & & \multicolumn{7}{c}{ Elements, weight\% } \\
\cline { 3 - 9 } Sl. No & Material used & $\mathrm{C}$ & $\mathrm{Si}$ & $\mathrm{Mn}$ & $\mathrm{S}$ & $\mathrm{P}$ & $\mathrm{Mg}$ & $\mathrm{Ti}$ & $\mathrm{Fe}$ \\
\hline & & 0.18 & 0.18 & 0.98 & 0.016 & 0.016 & - & - & bal \\
& IS:2062 (base metal) & Titanium carbide (TiC) (PTA powder) & 0.04 & 0.03 & 0.03 & - & - & 0.09 & 99.0 & 0.12 \\
\hline
\end{tabular}


tions as shown in Table 2. Hardfaced plate and typical cross section are shown in Figure 1 and Figure 2 respectively.

The transverse sections of all the hardfaced samples were metallographicaly polished and etched. After etching and washing with distilled water, the specimens were subjected to microhardness, microstructure and wear resistance survey.

Microhardness: A Mitutoya (MVK-HI) microhardness tester was used to conduct the microhardness analysis

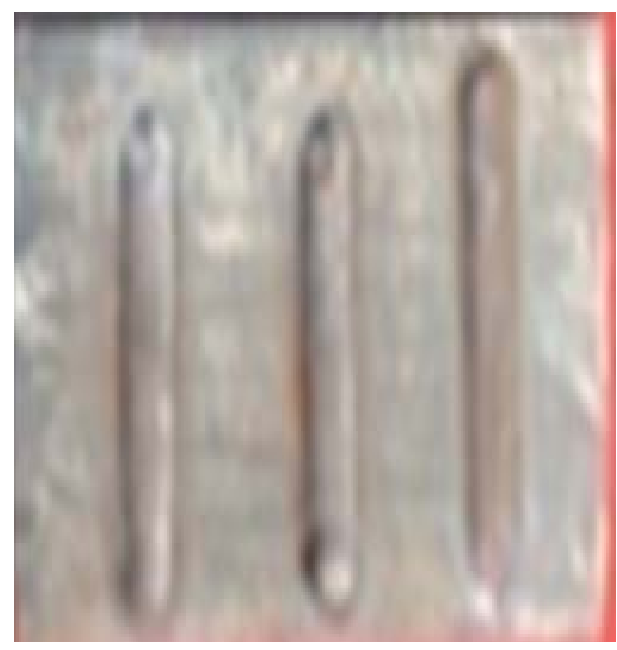

Figure 1. Photograph of hardfaced plate.

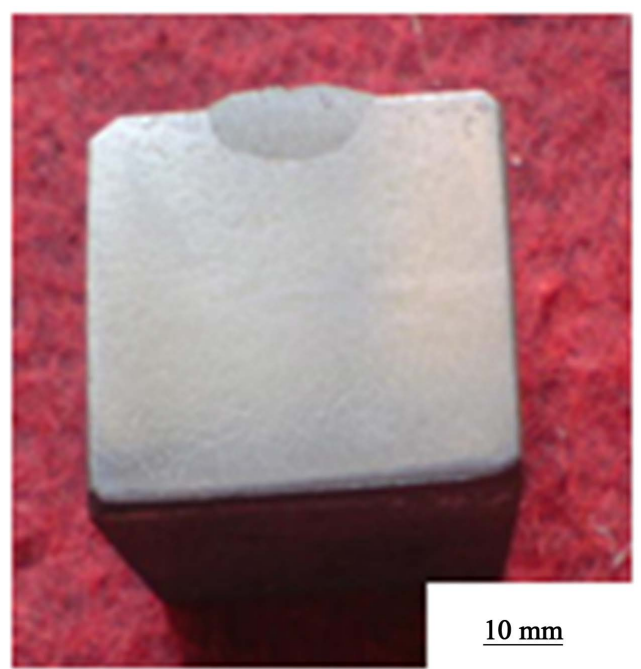

Figure 2. Typical cross section of hardfaced plate.

Table 2. PTA hardfacing experimental conditions.

\begin{tabular}{|c|c|c|c|c|c|c|c|c|}
\hline \multirow{2}{*}{ Sl. No } & \multicolumn{5}{|c|}{ Parameters } & \multirow{2}{*}{ \% Dilution } & & \multirow{2}{*}{ Heat input, kJ/mm } \\
\hline & I & S & $\mathrm{F}$ & $\mathrm{H}$ & $\mathrm{T}$ & & & \\
\hline 1 & 160 & 140 & 16 & 10 & 290 & 36.11 & 15.14 & Low Heat Input (LHI) \\
\hline 2 & 205 & 130 & 14 & 9 & 260 & 34.49 & 18.85 & Medium Heat Input (MHI) \\
\hline 3 & 190 & 120 & 16 & 10 & 290 & 29.81 & 20.98 & High Heat Input (HHI) \\
\hline
\end{tabular}

$\mathrm{I}$ = welding current (amps); $\mathrm{S}=$ welding speed $(\mathrm{mm} / \mathrm{min}) ; \mathrm{F}=$ powder feed rate $(\mathrm{gm} / \mathrm{min}) ; \mathrm{H}=$ oscillation width $(\mathrm{mm}) ; \mathrm{T}=$ pre heat temperature $\left({ }^{\circ} \mathrm{C}\right)$. 
on the hardfaced specimens starting from the base metal up to the weld metal along the centre line. During microhardness tests, vickers indenter with $100 \mathrm{gm}$ load was applied to make the indentations in all specimens. The microhardness vales obtained from the survey were plotted against the distance across the interface of the weld cross section in graphical form for a thorough analysis.

Microstructure: The prepared samples were etched with an etchant consists of 2 - 3 gram sodium molybdate, $5 \mathrm{ml}$ hydrochloric acid (35\% concentration) and 1 - 2 gram ammonia bifluoride in $100 \mathrm{ml}$ distilled water for revealing the different zones of the weldments such as hardfaced metal, fusion zone, etc.

Sliding Wear Test: The pin-on-disc wear testing apparatus is used for conducting wear tests, under varying sliding speed and applied pressure against steel disc of hardness $500 \mathrm{HV}$. The pin samples of $25 \mathrm{~mm}$ length and $3 \mathrm{~mm} \times 3 \mathrm{~mm}$ were prepared from hardfaced plates and are shown in Figure 3. The surface of the pin sample and the steel disc were ground using emery paper (grit size 240) prior to each test. Each sample was subjected to sliding wear for an applied test load $(3 \mathrm{~N}, 5 \mathrm{~N}$ and $7 \mathrm{~N})$ at a constant sliding velocity $2 \mathrm{~m} / \mathrm{s}$. Weight loss of the specimen was measured every $200 \mathrm{~m}$ of sliding distance travelled by the pin. The test was integrated with WINDUCOM software and the wear loss was recorded. The specimen cleaned with acetone and weighted using an electronic weighing machine with an accuracy of $0.001 \mathrm{~g}$ prior to and after each test to determine the weight loss. The difference in weight gives the wear loss of the specimen. The wear rate was calculated from the weight loss measurement and expressed in terms of volume loss per unit sliding distance as given below.

Wear volume, $\mathrm{m}^{3}=$ weight loss/density.

Wear rate, $\mathrm{m}^{3} / \mathrm{m}=$ wear volume/sliding distance.

\section{Result and Discussion}

\subsection{Microhardness}

It is evident from Figures 4-6 that the hardness of weldmetal near FBZ is lower than that of the weld metal away from the FBZ indicating the effect of dilution. In Figure 4, the hardness adjacent to the interface is found

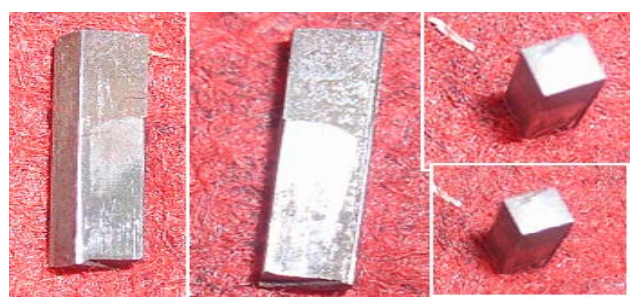

Figure 3. Pin samples for wear tests.

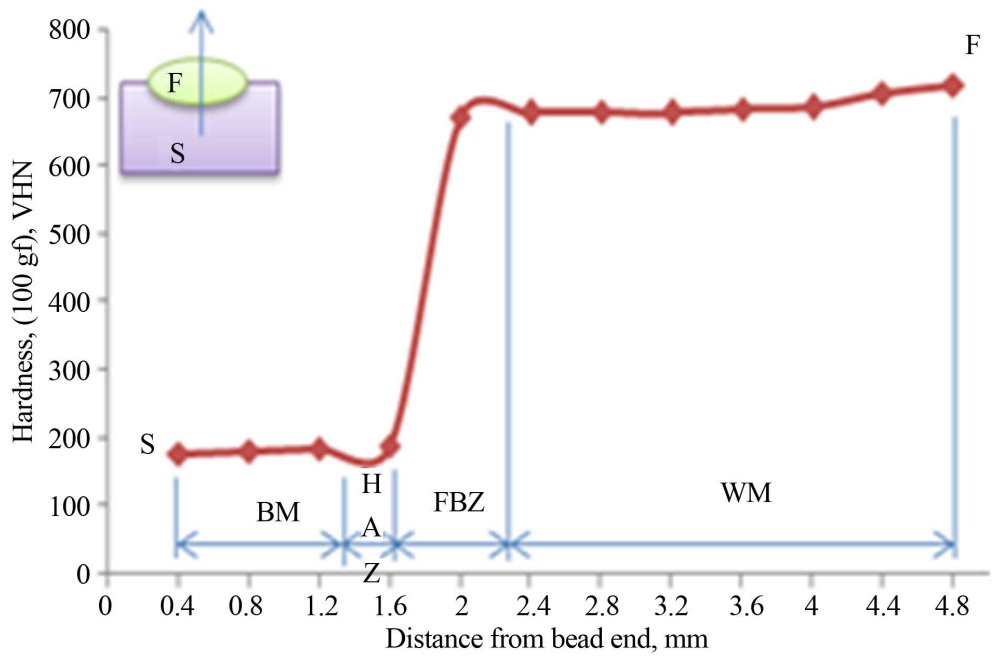

Figure 4. Microhardness distribution along various zones of PTA hardfacing for LHI $(15.14 \mathrm{~kJ} / \mathrm{mm})$. 


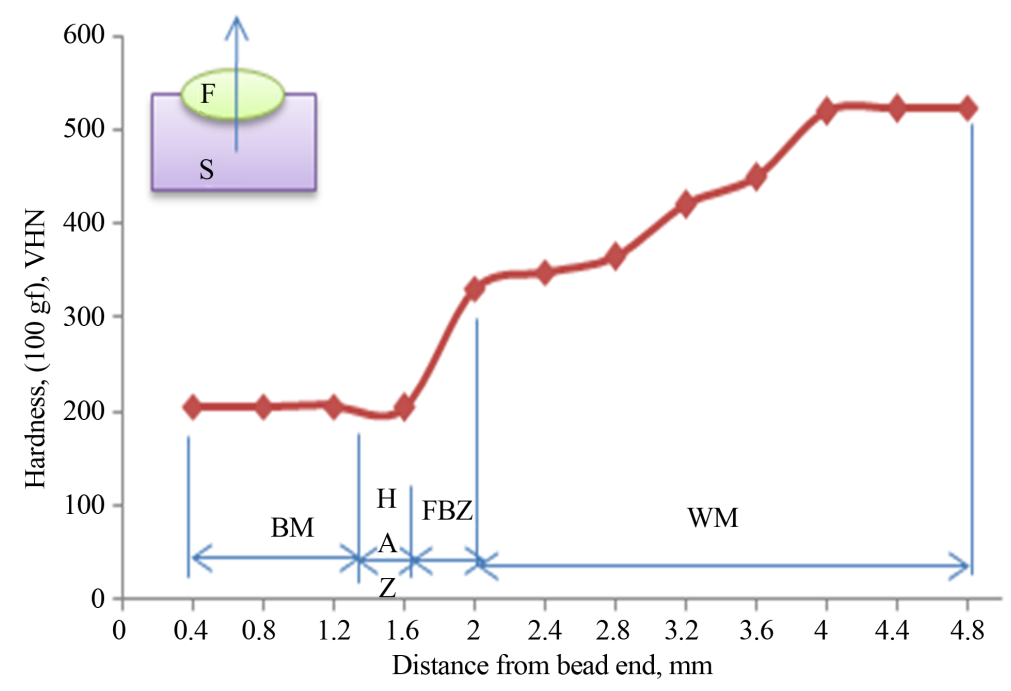

Figure 5. Microhardness distribution along various zones of PTA hardfacing for MHI $(18.84 \mathrm{~kJ} / \mathrm{mm})$.

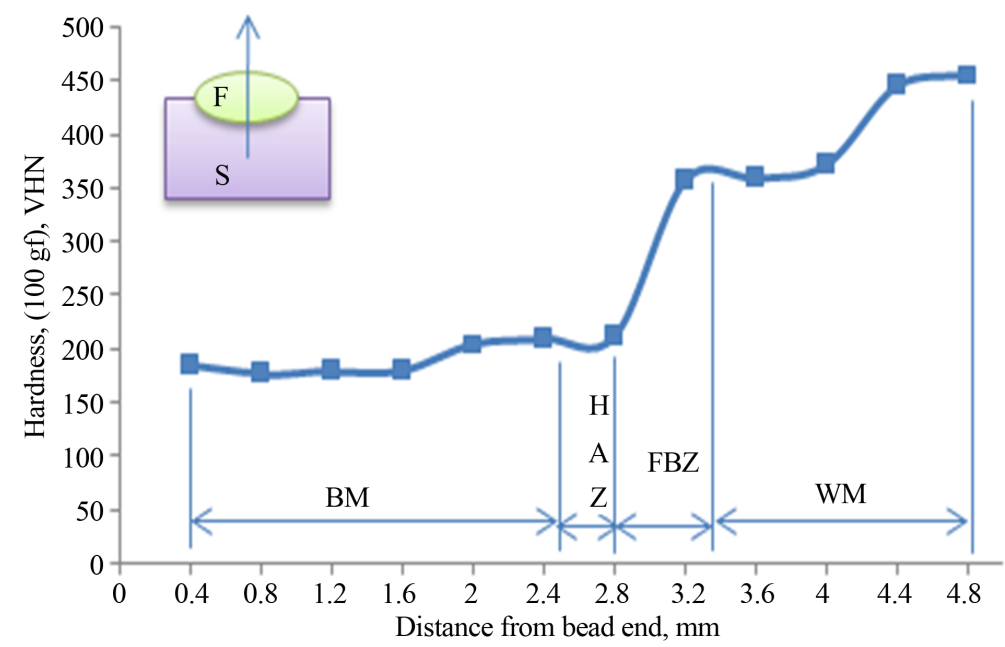

Figure 6. Microhardness distribution along various zones of PTA hardfacing for HHI (20.98 kJ/mm).

to be $\sim 650$ VHN which is much lower than that of hardness measured away from the interface, i.e. $~ 700$ VHN. It is due to the effect of dilution observed near the interface. It is observed from Figure 5 and Figure 6 that the microhardness value decreases when heat input is increased. It is attributed to change in dilution caused by the respective magnitude of heat input. Therefore from Figures 4-6 it is found that an increase in heat input reduces the hardness of PTA hardfacing.

\subsection{Microstructure}

The results obtained from the microstructural observation are presented below:

The photomicrographs taken at different magnification for all the samples welded at low, medium and high heat input conditions are presented.

It is evident from Figure 7 that the ferrite-pearlite microstructure of the HAZ. The colored microstructure reveals the matrix of ferrite (yellowish, brownish and white) ferrite and dark banded pearlite phases. Typical microstructural changes that occur when IS 2062 structural steel is heated to the vicinity of the eutectoid reaction $\sim 727^{\circ} \mathrm{C}$ and cooled to ambient temperature. The various regions (i.e. HHI, MHI and LHI) where conversion to an austenite matrix (on heating) occurred followed by a retransformation to a ferrite matrix on cooling. It is 

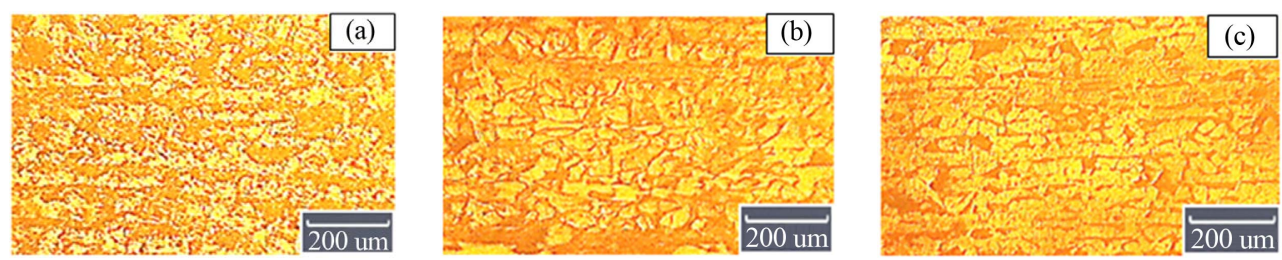

Figure 7. Photomicrograph showing the microstructure of the HAZ: (a) LHI (b) MHI and (c) HHI.

found that heat input increases grain coarsening occurs.

It is evident from Figures 8-10 that microstructures of hardfaced plates at different heat input like HHI, MHI and LHI conditions reveal coarser precipitates of carbides and TiC. When the heat input increases, a slight tendency for the elements (C, Mn, Si) to decrease in the composition. It can be seen that the most TiC particles had a faceted morphology and were uniformly dispersed in the steels, but a slight agglomeration was observed in the steel with the increase of carbon content in the matrix steels the volume fraction of TiC particles increased while the size of them decreased.

The reinforcing particles are idiomorphic crystals of polygonal almost uniformly dispersed in the ferrous matrix, which consists of a fine ferrite microstructure. The form of the reinforcing particles is clearly different from the globular form of the powder grains used for the preparation of the hardfacing; their respective size distribution is also quite different. These remarks confirm that during the PTA melting process the TiC powder was dissolved completely in the melt coming from the substrate. Therefore, the microstructure of the hardfacing resulted from a solidification process and is characteristic of an "in situ composite."

The reinforcing particles' volume fraction was found that it could be somewhat higher on the external surface of the coatings, because the $\mathrm{TiC}$ particles have a lower density than the ferrous melt and tend to rise to the surface. This phenomenon is, however, limited due to the high solidification rate of the process. The hardness of the transition zone was found to be below $400 \mathrm{VHN}$ due to low-carbon levels and lower dilution achieved in hardfacing. Hardfacing solidified initially with planar or cellular structure and then gradually changed to cellular-dendritic structure depending upon the heat input condition and the dilution involved. Color metallography revealed three modes of solidification of stainless steel hardfacing and observed modes of solidification were in good agreement.

Figures 11-13 show that the presence of interface between structural steel substrate and hardfaced. This band formation is due to the attainment of high temperature during hardfacing. It is clear from the microstructures that with increase in heat input the width of the fusion boundary zones also increases. The microstructure consisted of TiC dendrites embedded in an eutectic matrix consisting of small polygonal TiC crystals and ferrite. The micro-structure was interpreted in terms of the ternary Fe-Ti-C phase diagram, which allowed anticipating that, during the solidification process, TiC separated first from the melt as primary dendritic crystals and then, at a lower temperature range, polygonal TiC crystals of smaller size formed within a ferrous matrix along a eutectic valley of the ternary diagram.

Being alloyed with titanium, in addition to the small, homogeneously distributed carbides contains a titanium additive, giving the steel structure reinforcement with very fine and extremely hard titanium carbides (TiC) that have hardness. These carbides give the steel a significantly higher wear resistance. It has been designed to make use of several metallurgic aspects: Hardness increase in use; the strengthening of the steel structure with titanium carbides.

The process requires only sufficient application of heat to obtain a sound bond with the parent metal. Admixtures of the two metals are minimized. Using too much heat during hardfaced welding will dilute the hardfaced alloys with the base metal, thereby reducing effective wear resistant properties of the material. Excessive heats will vaporize the alloys and will cause oxidation. Overly heated weld puddles can further result in such fluid condition of the alloys that they create a thinner deposit than may be intended. Insufficient welding heat, on the other hand, will cause weak bonds with the base metal and can possibly result in spalling.

\subsection{Wear Properties}

It may be important to explain the difference in wear behavior of hardfacing produced under different heat input conditions. The average wear and wear rate are show in Table 3. 


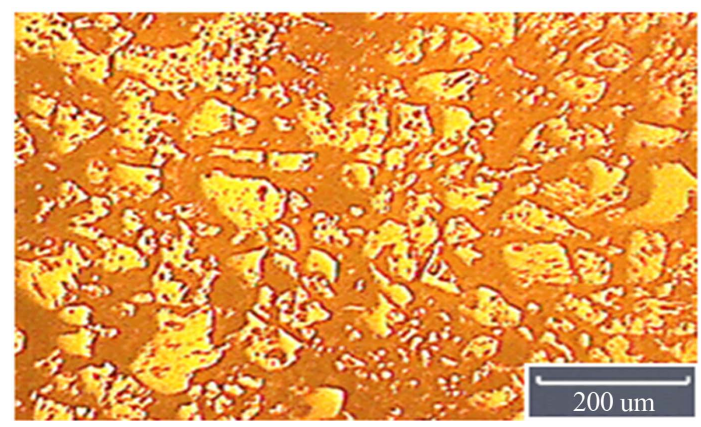

Figure 8. Photomicrograph showing the structure of the hardfaced at LHI condition.

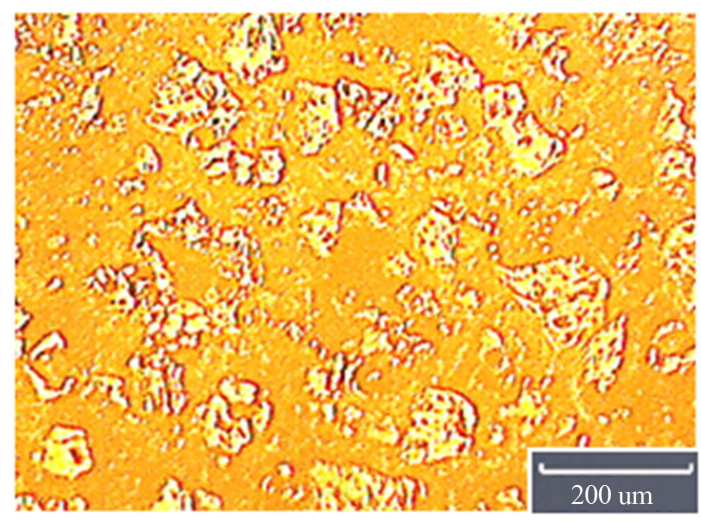

Figure 9. Photomicrograph showing the structure of the hardfaced MHI condition.

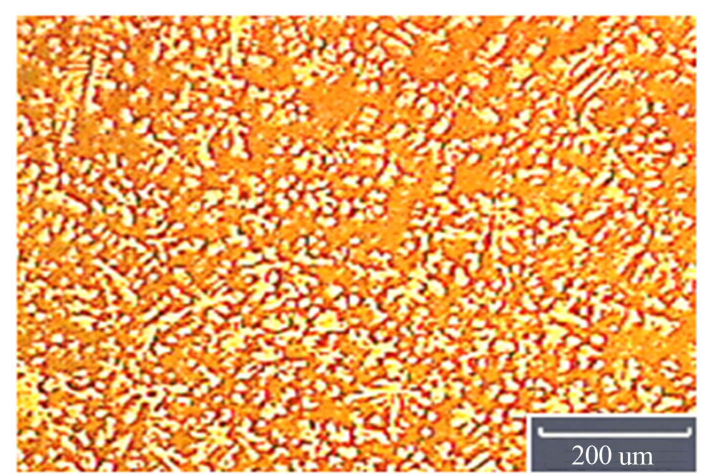

Figure 10. Photomicrograph showing the structure of the hardfaced at HHI condition.

Table 3. Wear properties of hardfacing.

\begin{tabular}{|c|c|c|c|c|c|c|c|c|}
\hline \multirow{3}{*}{ Sl. No } & \multirow{3}{*}{$\begin{array}{l}\text { Normal load } \\
\text { (N) }\end{array}$} & \multirow{3}{*}{$\begin{array}{c}\text { Sliding } \\
\text { velocity }(\mathrm{m} / \mathrm{s})\end{array}$} & \multicolumn{6}{|c|}{ Wear properties } \\
\hline & & & \multicolumn{3}{|c|}{ Wear $(\mu \mathrm{m})$} & \multicolumn{3}{|c|}{ Wear rate, $10^{8}\left(\mathrm{~m}^{3} / \mathrm{m}\right)$} \\
\hline & & & LHI & MHI & HHI & LHI & MHI & $\mathrm{HHI}$ \\
\hline \multirow{3}{*}{1} & 3 & 2 & 0.63 & 0.69 & 0.81 & 1.07 & 1.08 & 1.11 \\
\hline & 5 & 3 & 1.55 & 1.56 & 1.60 & 1.18 & 1.31 & 1.41 \\
\hline & 7 & 4 & 2.11 & 2.23 & 2.30 & 1.32 & 1.45 & 1.58 \\
\hline
\end{tabular}




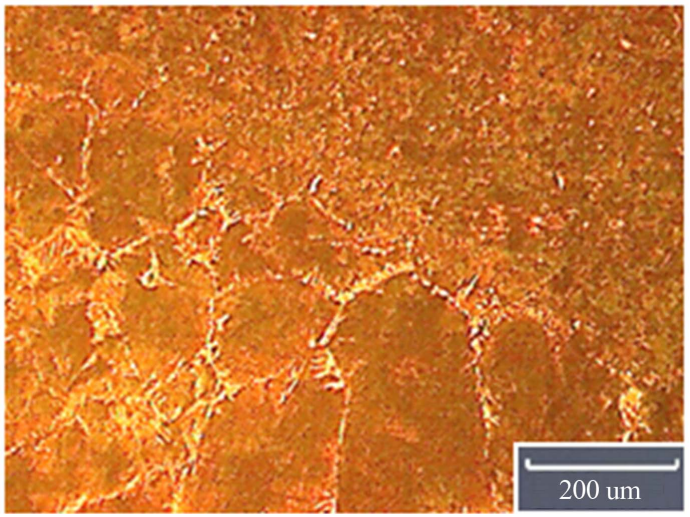

Figure 11. Photomicrograph showing the structure of the interface surface at LHI condition.

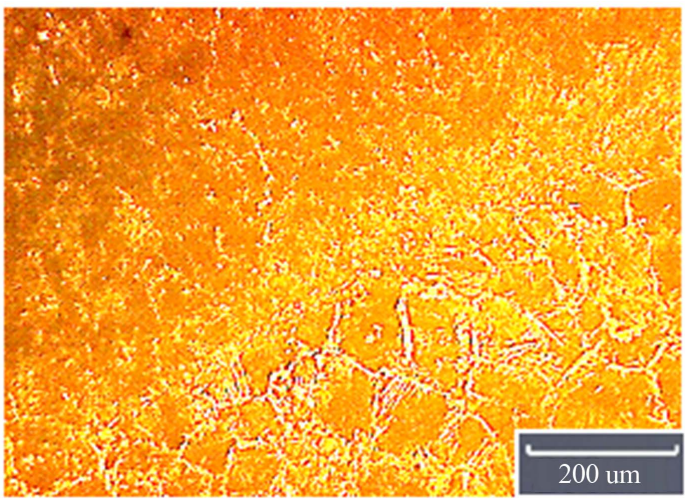

Figure 12. Photomicrograph showing the structure of the interface surface at MHI condition.

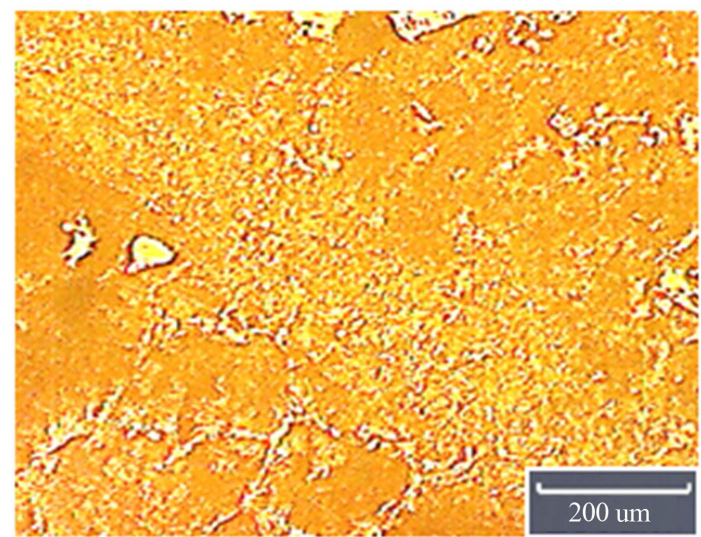

Figure 13. Photomicrograph showing the structure of the interface surface at HHI condition.

It is found that for a low heat input hardfacing, at $3 \mathrm{~N}$ and $5 \mathrm{~N}$ loads up to an initial sliding distance of $400 \mathrm{~m}$, there is no significance in wear. Increase in normal load generally increases the wear rate under identical sliding conditions. At a higher load $7 \mathrm{~N}$ wear increases from the beginning itself and the amount of wear is much greater than that occurred for low loads. The weight loss for as hardfaced MHI and HHI is more than that of LHI. The increased weight loss obtained in the case of high heat input hardfaced layer resulting from high heat input provided during the process on the abrasive wear resistance. 


\section{Conclusions}

- Dilution of TiC deposited by PTA hardfacing at different heat input conditions has an significant effect on the microstructure and hardness of the deposit.

- Hardness varies across the deposit/substrate interface of low heat input where as it gradually varies for medium and high heat input.

- Maximum hardness of fusion zone is larger for low heat input than that of the medium and high heat input.

- The volume fraction of precipitates of carbides and TiC is higher in the case of low heat input.

- Dendritic formations are seen in the high heat input hardfaced layer.

- Primary carbides are refined gradually with the increase in titanium content. The morphology changes from a bulk form to a refined one.

- Sliding abrasive wear increases with increase in normal load under identical sliding conditions. The hardfaced layer deposited at low heat input condition has lower wear rate than that of medium and high heat input conditions.

\section{References}

[1] Su, Y.L. and Chen, K.Y. (1997) Effect of Alloy Additions on Wear Resistance of Nickel in Pulsed GMAW. Welding Journal, 76, 143s-150s.

[2] Zhang, Q.H. and Yin, B.Y. (2006) Microstructure and Wear Properties of TiC-VC Reinforced Iron Based Hardfacing Layers. Institute of Materials, Minerals and Mining Published by Maney on Behalf of the Institute.

[3] Zollinger, O.O., Beckham, J.E. and Monroe, C. (1998) What to Know before Selecting Hardfacing Electrodes: Special Emphasis: Developments in Welding Electrodes. Welding Journal, 77, 39-43.

[4] Jha, A.K., Prasad, B.K., Dasgupta, R. and Modi, O.P. (1999) Influence of Material Characteristics on the Abrasive Wear Response of Some Hardfacing Alloys. Journal of Materials Engineering and Performance, 8, 190-196. http://dx.doi.org/10.1361/105994999770347034

[5] Davis, J.R., Davis and Associates (1994) Hardfacing, Weld Cladding and Dissimilar Metal Joining. ASM HandbookWelding, Brazing and Soldering, Vol. 6, 10th Edition, ASM Metals Park, OH, 699-828.

[6] Lugscheider, E., Morkramer, U. and Ait-Mekideche, A. (1991) Advances in PTA Surfacing. Proceeding of the 4th National Thermal Spray Conference, Pittsburgh.

[7] D’Oliveira, A.S.C.M. (2005) Pulsed Current Plasma Arc Welding. Journal of Material Processing Technology, 171, 167-174. http://dx.doi.org/10.1016/j.jmatprotec.2005.02.269

[8] Wang, X.B. (1998) Metal Powder Thermal Behavior during the PTA Surfacing Process. Surface and Coatings Technology, 156-161.

[9] Liu, C.S., Huang, J.H., Zhao, Y. and Liu, M. (2000) Transactions of Nonferrous Metals Society of China, 10, $405-407$.

[10] Gonzalez, C. and Llorca, J. (2001) Micromechanical Modeling of Deformation and Failure in Ti-6Al-4V/SiC Composites. Acta Materialia, 49, 3505-3519. http://dx.doi.org/10.1016/S1359-6454(01)00246-4

[11] Fu, Y.-C., Shi, N.-L., Zhang, D.-Z. and Yang, R. (2004) Preparation of SiC/Ti Composites by Powder Cloth Technique. The Chinese Journal of Nonferrous Metals, 14, 465-470.

[12] Ding, H.-M., Liu, X.-F., Lin, Y. and Zhao, G.-Q. (2007) The Influence of Forming Processes on the Distribution and Morphologies of TiC in Al-Ti-C Master Alloys. Scripta Materialia, 57, 575-578. http://dx.doi.org/10.1016/j.scriptamat.2007.06.028

[13] Hill, D., Banerjee, R., Huber, D., Tiley, J. and Fraser, H.L. (2005) Formation of Equiaxed Alpha in TiB Reinforced Ti Alloy Composites. Scripta Materialia, 52, 387-392. http://dx.doi.org/10.1016/j.scriptamat.2004.10.019

[14] Falat, L., et al. (2005) Mechanical Properties of Fe-Al-M-C (M = Ti, V, Nb, Ta) Alloys with Strengthening Carbides and Laves Phase. Intermetallics, 13, 1256-1262. http://dx.doi.org/10.1016/j.intermet.2004.05.010

[15] Dóllar, A. and Dymek, S. (2003) Microstructure and High Temperature Mechanical Properties of Mechanically Alloyed $\mathrm{Nb}_{3} \mathrm{Al}$ Based Materials. Intermetallics, 11, 341-349. http://dx.doi.org/10.1016/S0966-9795(03)00002-5

[16] Weman, K. (2003) Welding Processes Handbook. CRC Press LLC, New York.

[17] Puntharani, K. and Murugan, N. (2010) Finite Element Simulation for Prediction of Bead Geometry and Resudual Stesses in Stellite Hardfacing Gate Valve by PTAW Process. International Journal of Advanced Manufacturing Technology. 